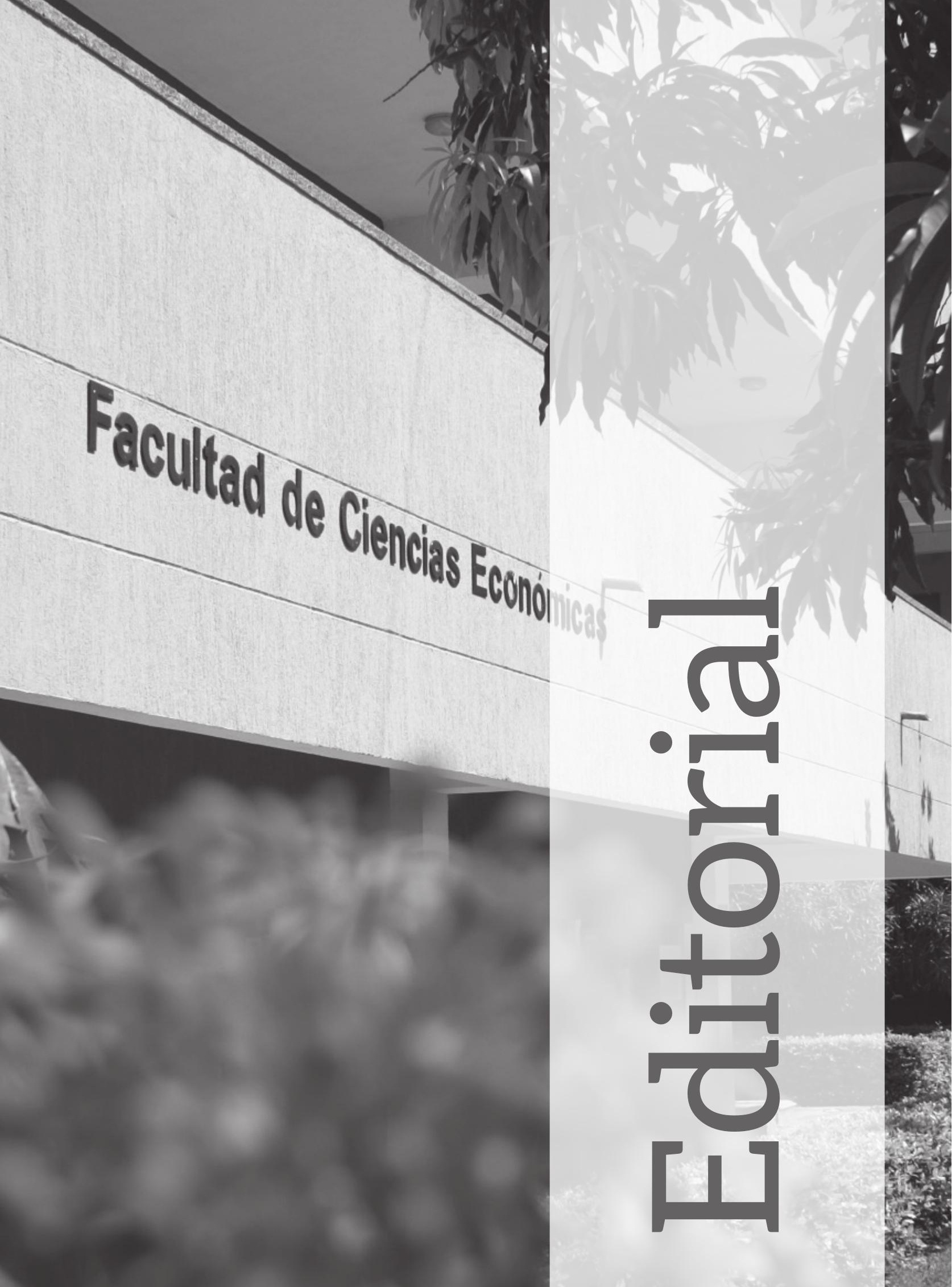





\section{Historia, Economía y Sociedad}

Rafael E. Acevedo P.' Universidad de Cartagena

Andrés Escobar E. ${ }^{2}$ Universidad de Cartagena

En la actualidad, una de las preocupaciones centrales de las disciplinas adscritas a las ciencias económicas, sociales y humanas tiene que ver con la necesidad de poner en diálogo los diversos saberes que se producen desde un campo académico, con la finalidad así de lograr construir un conocimiento más integral sobre los desarrollos y obstáculos de las sociedades. Teniendo en cuenta esa premisa, que invita a trascender las fronteras disciplinares, la revista Panorama Económico, publicación de la Universidad de Cartagena, presenta al público lector un nuevo número dedicado al estudio de las prácticas económicas en Colombia desde el punto de vista histórico. Hemos querido en esta ocasión reunir un conjunto de trabajos, resultados de proyectos de investigación, que señalan posibles rutas de análisis y puntos de encuentros entre la Economía y la Historia a propósito de la comprensión de los órdenes políticos, las comunidades, las actividades mercantiles, las fábricas, la ciencia, las redes de comercio, el territorio y los múltiples actores sociales que dinamizaron la economía tanto en la sociedad colonial del siglo XVIII como en la República de Colombia del siglo XIX y XX.

El dossier que aquí presentamos es una evidencia de las relaciones disciplinares que existen y se pueden seguir tejiendo en términos temáticos, metodológicos y teóricos entre la Historia y la Economía, disciplinas que siempre han estado en una constante comunicación, hasta tal punto que tanto a nivel nacional como internacional se cuentan con valiosos análisis desprendidos de grupos y líneas de investigación en historia económica, historia empresarial, historia del pensamiento económico, historia social de las practicas económicas, historia de las instituciones e incluso, en otros de los casos, hasta se han compartido metodologías, más allá de los procedimientos estadísticos, como en su momento y todavía hoy lo sigue proponiendo -por colocar un ejemplo- la cliometría.

1. Editor invitado. Contacto: racevedop@unicartagena.edu.co

2. Editor en jefe. Contacto: aescobare@unicartagena.edu.co 
Desde luego, este dossier no pretende poner en escena todos los diálogos posibles entre la Economía y la Historia como disciplinas, por el contrario ha sido nuestro objetivo invitar a los historiadores a reflexionar sobre un problema que es común en todos los artículos: las prácticas económicas como una dimensión constitutiva del pasado y de la organización de las sociedades en sus propios contextos. Inclusive, la problemática abordada hemos querido reducirla al caso de la sociedad colonial y la República de Colombia en el siglo XIX y XX, con la finalidad de que el lector pueda tener una imagen más concreta sobre los diferentes ritmos y las diversas actividades económicas en ese territorio, lo cual no quiere decir que los textos -en algunos casos-no muestren las conexiones que existían desde ese territorio con el escenario internacional por vía de su articulación con la Monarquía española, por vía de las redes comerciales y familiares, o por vía del ejercicio de lo político, de la dinámica de los mercados y del establecimiento de pequeñas empresas y fábricas.

Además, es importante señalar que el dossier está pensado conforme a algunos problemas comunes que se presentaron tanto en la sociedad colonial como en la República de Colombia, pero que fueron resueltos de diversas maneras en el escenario de las localidades. Es por ello que hemos organizado los textos en función a problemáticas que dialogan entre si y no siguiendo una cronología lineal. Desde luego, no se trata tampoco de decir que los objetos de estudio abordado sean una síntesis de las principales preocupaciones económicas tanto en el mundo neogranadino del siglo XVIII como en la comunidad política republicana de la primera mitad del siglo XIX, o durante el proceso de formación del estado nacional colombiano después de la segunda mitad del siglo XIX y en el XX.

En ese orden de ideas, el dossier abre sus páginas con tres artículos que guardan una relación entre sí -aunque desde distintos matices y abordando diferentes espacios y temporalidades- en torno al problema de la vinculación a los órdenes políticos existentes por vía de las practicas económicas. En un primer momento Jorge Conde Calderón y Hugues Sánchez Mejía nos muestran como durante el siglo XVIII muchos sitios de libres lograron integrarse al orden hispánico, integración que estuvo marcada por la condición de vecindad que obtuvieron algunos libres (negros, mulatos, pardos y zambos), que valió en muchos casos para acceder a empleos y desempeñar algunas actividades económicas. (Calderón y Sanchez, 2019). Seguidamente, Paola Ruiz analiza los distintos reclamos que hicieron a favor del libre comercio las autoridades del Istmo de Panamá para vincularse al orden político republicano en la primera mitad del siglo XIX, con la finalidad de recuperar el control sobre los puertos francos y por tanto lograr así recobrar el antiguo esplendor comercial que habían ostentado en la época colonial. (Ruiz, 2019). Y finalmente, José Polo Acuña recrea las diversas actividades empresariales y comerciales (explotación de madera, cría, levante y venta de ganado, aprovechamiento de las tierras, impulso de la banca, los créditos, la compra-venta de acciones, el establecimiento de compañías, entre otras) emprendidas por la familia francesa Dereix en la frontera del Valle del Sinú, lo cual fue significativo para poner esa zona fronteriza en sintonía con las dinámicas del mercado nacional y de la economía mundial en el periodo de 1896-1950. (Polo 2019). 
Asimismo, en el dossier encontramos dos artículos que abordan el problema de la salud y su vinculación con las actividades económicas en contextos distintos. Vladimir Daza ofrece un análisis detallado de la crisis fiscal durante las guerras de la independencia en la Nueva Granada, entre 1815-1819, como uno de los detonantes principales de la crisis de la salud y, por tanto, de la propagación de enfermedades como la malaria, la fiebre amarilla y la viruela, enfermedades que debido a la escasez de recursos para combatirlas incidieron en el debilitamiento de las tropas en contienda, hasta tal punto que fue una de las consecuencias principales de la derrota de los ejércitos expedicionarios de España en territorio americano en la tercera década del siglo XIX. (Daza 2019). A propósito de la relación entre salud y actividades económicas, haciendo uso de los enfoques metodológicos de la historia empresarial, María Fernanda Erazo Obando estudia el mercado de medicamentos impulsado por la familia Garcés en la ciudad de Cali desde la segunda mitad del siglo XIX y durante los tres primeros decenios del XX, mostrando las producciones y la importación de medicamentos desde Estados Unidos, Alemania, Suiza, entre otros países; las transformaciones de las boticas en droguerías; la elaboración de laboratorios propios de productos medicinales artesanales como las farmacias; y la posterior conversión de esos laboratorios en industrias farmacéuticas nacionales. (ErazoObando, 2019).

Por último, el dossier cierra sus páginas con un artículo dedicado a uno de los problemas centrales de la sociedad republicana y nacional: los ingresos fiscales de los entes territoriales locales. Un aspecto ése que se estudia en el artículo de José Ángel Villalba Hernández, quien logra demostrar, a partir de un análisis estadístico, como durante el gobierno de la regeneración entre 1882-1899, a pesar del proyecto político centralista, ciudades como Cartagena pudieron sobreponerse a la "crisis fiscal" y garantizaron el bienestar de su población mediante la inversión y el avance en obras de infraestructura, educación, vías de comunicación, transporte, entre otros aspectos. Desde luego, una situación ésta que invita a analizar, sin desconocer los conflictos y desacuerdos que se presentaron, el impulso y la contribución de la economía regional al proceso de formación de la economía del Estado Nacional colombiano a fines del siglo XIX y principios del XX. (Villalba, 2019).

Estamos, pues, frente a un dossier donde el análisis económico e histórico no se reducen a una discusión teórica, sino que se establece sobre la base del trabajo empírico, es decir, de estudios de casos que muestran las actividades económicas como un pilar fundamental en la estructuración y las transformaciones de las sociedades del pasado. Una clara invitación ésta que nace del trabajo compartido y del intercambio de experiencias académicas entre el grupo de investigación Economía Aplicada, de la Facultad de Ciencias Económicas de la Universidad de Cartagena, y el de Sociedad, ciencia y cultura, de la Facultad de Ciencias Humanas de esa misma Universidad. 


\section{REFERENCIAS}

Conde-Calderón, J., Sánchez-Mejía, H. (2019). La Integración política de negros, mulatos, pardos y zambos al orden hispánico: Los sitios de libres en el nuevo reino de Granada. Panorama Económico, 4, 746-764.

Daza-Villar, V. (2019). Entre la malaria, la fiebre amarilla, la viruela y la crisis fiscal en la Guerra de Independencia, 1815-1819. Panorama Económico, 816-841.

Erazo-Obando, M. (2019). Una empresa tradicional del sector de medicamentos en Colombia: El caso de Farmacia y Droguería Garcés, 1876-1930. Panorama Económico, 4, 842-868

Polo-Acuña, J. (2019). Las actividades empresariales y comerciales de una familia de origen francés en Colombia. El caso de la familia Dereix, 1896-1950. Panorama Económico, 4, 787-815.

Ruiz, P. (2019). La libertad de comercio en el Istmo de Panamá: El debate político y fiscal a propósito de la "peculiaridad" panameña, 1821-1850. Panorama Económico, 4, 765-786.

Villalba-Hernández, J. (2019). Efectos fiscales de la Regeneración en Cartagena (1882-1899). Panorama Económico, 4, 869-902. 


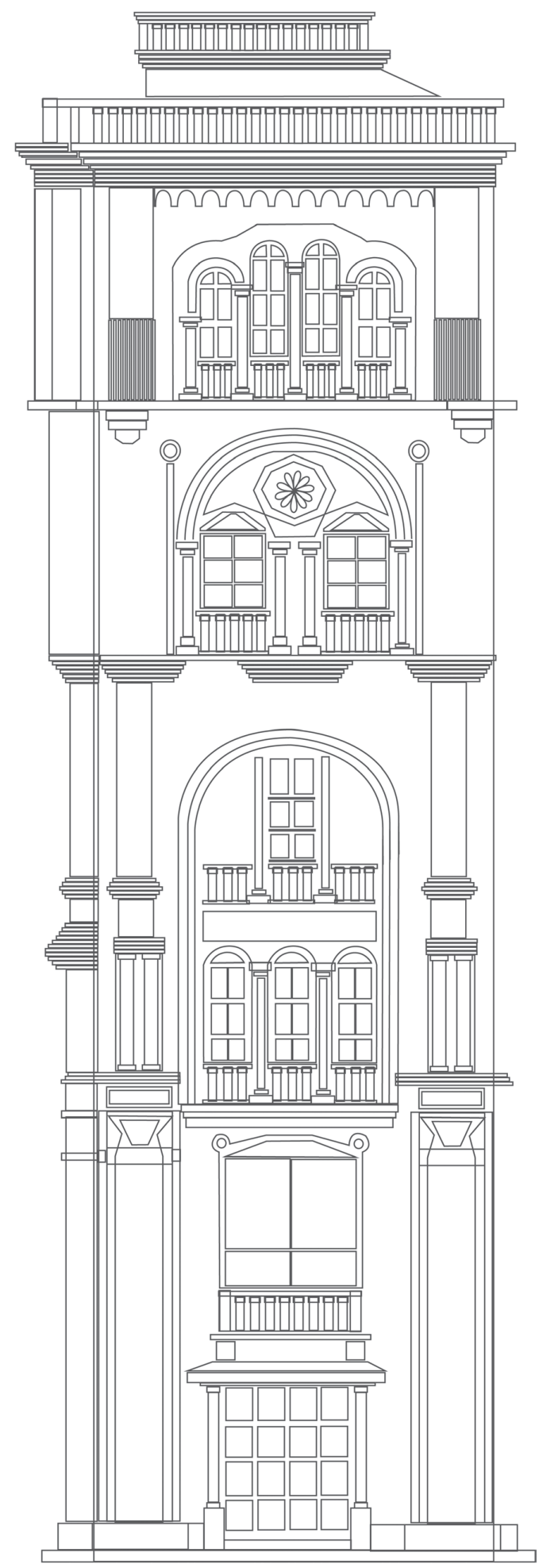

